\title{
Effect of lanthanum and lead doping on the microstructure and visible light photocatalysis of bismuth titanate prepared by the oxidant peroxide method (OPM)
}

\author{
André E. Nogueira ${ }^{\mathrm{a}, *}$, Alan R.F. Lima ${ }^{\mathrm{a}}$, Elson Longo ${ }^{\mathrm{b}}$, Edson R. Leite ${ }^{\mathrm{a}}$, Emerson R. Camargo ${ }^{\mathrm{a}}$ \\ a LIEC-Laboratório Interdisciplinar de Eletroquímica e Cerâmica, Departamento de Química, UFSCar-Universidade Federal de São Carlos, Rod. Washington Luis \\ km 235, CP 676 São Carlos, SP 13565-905, Brazil \\ b Instituto de Química de Araraquara, UNESP-Universidade Estadual Paulista, Rua Francisco Degni, CP 355 Araraquara, SP 14801-907, Brazil
}

\section{A R T I C L E I N F O}

\section{Article history:}

Received 16 May 2015

Received in revised form 9 July 2015

Accepted 22 July 2015

Available online 28 July 2015

\section{Keywords:}

Bismuth titanate

Chemical synthesis

Photocatalysis

Optical properties

\begin{abstract}
A B S T R A C T
Pure $\left(\mathrm{Bi}_{12} \mathrm{TiO}_{20}\right)$ and $\mathrm{La}$ - and $\mathrm{Pb}$-doped $\left(\mathrm{Bi}_{12-x} \mathrm{La}_{x} \mathrm{TiO}_{20}\right.$ e $\mathrm{Bi}_{12-x} \mathrm{~Pb}_{x} \mathrm{TiO}_{20}$, with "x" up to 1.50) bismuth titanates were prepared by the oxidant peroxide method (OPM) and used for photodegradation of rhodamine $\mathrm{b}(\mathrm{RhB})$. The synthesized materials samples were characterized by X-ray diffraction (XRD), UV-vis diffuse reflectance spectra (DRS), X-ray photoluminescence (PL) spectroscopy, scanning electron microscopy (SEM), X-ray fluorescence (XRF) and $\mathrm{N}_{2}$ physical adsorption. Rietveld refinements showed samples consisting mainly of sillenite structure with small amounts of a perovskite secondary phase in the La- and $\mathrm{Pb}$-doped materials. The photocatalytic properties of all materials were evaluated by the discoloration of RhB solution under ultraviolet (UV) and visible irradiation, where the bismuth titanate obtained by the OPM route showed higher photocatalytic activity than the commercial $\mathrm{TiO}_{2}$. Furthermore, it was observed that the insertion of different ions in the bismuth titanate structure changes the band gap energy in different ways, which consequently altered the photocatalytic activities of the materials.
\end{abstract}

(c) 2015 Elsevier B.V. All rights reserved.

\section{Introduction}

With the technological development initiated in the industrial revolution and intensified in the second half of the twentieth century, industrial processes have become essential for modern society. However, the current unsustainable patterns of production and consumption have caused serious damage to the environment due to the generation and disposal of waste in increasing quantity and complexity.

In relation to organic pollutants, we can highlight the high contamination power of textile dyes. Their strong coloring causes changes in biological cycles, mainly affecting the photosynthesis processes. Moreover, some classes of dyes and their byproducts may be carcinogenic and/or mutagenic [1]. Thus the need arises to develop new technologies for wastewater treatment, as well as to reduce the high costs of existing technologies.

In this context, the Advanced Oxidation Processes (AOP's) come to meet these requirements, mainly due to their simplicity and high efficiency in the degradation of many organic pollutants [2].

\footnotetext{
* Corresponding authors.

E-mail address: andreesteves86@hotmail.com (A.E. Nogueira).
}

These processes are based on the formation of hydroxyl radicals $\left(\mathrm{HO}^{\bullet}\right)$ which are capable of oxidizing the contaminants to smaller and less polluting molecules or even mineralize them. Among the processes that involve the generation of the hydroxyl radical, one can cite the heterogeneous photocatalysis, $\mathrm{H}_{2} \mathrm{O}_{2} / \mathrm{UV}, \mathrm{O}_{3} / \mathrm{UV}, \mathrm{O}_{3} /$ $\mathrm{H}_{2} \mathrm{O}_{2}$, Fenton and photo Fenton, and other combined processes [3].

Many studies have demonstrated the degradation of organic pollutants such as phenol, chlorinated hydrocarbons, chlorophenols, insecticides, dyes and others, using the photocatalysis process in the presence of $\mathrm{TiO}_{2}$ under solar radiation [4-6]. However, due to the high energy required for activation of $\mathrm{TiO}_{2}$ for generating the hydroxyl radicals (band gap equal to $3.2 \mathrm{eV}$ ), the yield of the process is limited by the absorption of radiation up to $385 \mathrm{~nm}$, which corresponds to only about $5 \%$ of the solar spectrum $[7,8]$.

Considering these factors, the bismuth titanate presents itself as an alternative to be used as a photocatalyst due to the high absorption of radiation in the visible region $[9,10]$. The different polymorphs of bismuth titanate $\left(\mathrm{Bi}_{4} \mathrm{Ti}_{3} \mathrm{O}_{12}\right.$, and $\left.\mathrm{Bi}_{2} \mathrm{Ti}_{2} \mathrm{O}_{7} \mathrm{Bi}_{12} \mathrm{TiO}_{20}\right)$ can be obtained by changing the stoichiometric ratio of bismuth (Bi) and titanium (Ti) and various routes have been employed in their synthesis, such as the EDTA/citrates method [11], sol-gel process [12], solid-state reaction [13], and peroxide-based route $\left(\mathrm{H}_{2} \mathrm{O}_{2}\right)$ [14-16]. 
Through these routes, powders are obtained with the desired crystalline phase and nanosized. However, the precursors used provide some drawbacks such as the use of halides, alkoxides and carbonates, which are groups difficult to eliminate and that interfere in the photocatalytic activity of the materials.

A summary route still little studied by the wet chemical method, which became known as the oxidant peroxo method (OPM), was developed for the synthesis of oxide nanoparticles containing lead or bismuth in their composition [17,18]. The main innovation of this route was the possibility of obtaining nanosized ceramic powders of great technological and commercial interest, free of any contamination by carbon and halides. Other important characteristics of this new technique, which represented a huge environmental gain, is the exclusive use of water as a solvent, low temperature processing used for crystallization of nanosized oxides and the absence of any potentially toxic byproduct [19].

In the present work, La- and Pb-doped bismuth titanates were synthesized by the OPM method. The adsorption and photocatalytic activity of synthesized bismuth titanate powders was evaluated by examining the degradation of $\mathrm{RhB}$ dye solution under UV and visible light irradiation, assessing the effect of dopants on the optical properties and photocatalytic of the bismuth titanate.

\section{Materials and methods}

\subsection{Synthesis}

Pure $\left(\mathrm{Bi}_{12} \mathrm{TiO}_{20}\right)$, La-doped $\left(\mathrm{Bi}_{12-\chi} \mathrm{La}_{x} \mathrm{TiO}_{20}\right)$, and Pb-doped $\left(\mathrm{Bi}_{12-x} \mathrm{~Pb}_{x} \mathrm{TiO}_{20}\right)$ samples of bismuth titanate were prepared with $x=0.30$ (BLT2.5 and BPT2.5); 0.60 (BLT5 and BPT5); 1.20 (BLT10 and BPT10) and 1.50 (BLT15 and BPT15) through the dissolution of titanium metal powder (98\% Aldrich, USA) in an aqueous solution of $60 \mathrm{~mL}$ of $\mathrm{H}_{2} \mathrm{O}_{2}$ (30\%, analytical grade, Synth, Brazil) and $40 \mathrm{~mL}$ of ammonia solution (30\%, analytical grade, Synth, Brazil) (Camargo and Kakihana [19]). After approximately $3 \mathrm{~h}$, a yellow solution of peroxo complex was obtained. A second solution was prepared with $\mathrm{Bi}_{2} \mathrm{O}_{3}$ (99.99\%, Aldrich, USA) and $\mathrm{La}_{2} \mathrm{O}_{3}$ (Sigma-Aldrich, 99.99\% CAS 1312-81-8) or $\mathrm{Pb}\left(\mathrm{NO}_{3}\right)_{2}$ (Sigma-Aldrich, $99.99 \%$ CAS 10099-74-8) into $10 \mathrm{~mL}$ of nitric acid (analytical grade, Synth, Brazil) that was slowly added dropwise in the peroxo complex solution under stirring and cooling in an ice-water bath. This addition resulted in a vigorous gas evolution, forming an amorphous and yellow precipitate that was filtered and washed with diluted ammonia solution to eliminate all nitrate ions. The washed precipitate was dried at $60^{\circ} \mathrm{C}$ for $24 \mathrm{~h}$, ground and calcined at $700{ }^{\circ} \mathrm{C}$ for $1 \mathrm{~h}$ at a heating rate of $10^{\circ} \mathrm{C} \mathrm{min}^{-1}$ in closed alumina boats.

\subsection{Characterization}

The pure and doped materials were characterized at room temperature by X-ray diffraction. A Rigaku diffractometer (model D/MAX 200) equipped with graphite monochromator was used operating with $\mathrm{Cu}-\mathrm{K} \alpha$ radiation. Measurements were carried out over an angular range of $15^{\circ} \leq 2 \theta \leq 75^{\circ}$ with a scanning step of $0.02^{\circ}$ and a fixed counting time of $6 \mathrm{~s}$. The pure and doped bismuth titanates structures were refined according to the Rietveld method using the GSAS program [20]. The input data of the theoretical model were those available in the ICSD database (Code 40313 [21], 87811 [22] and 202923 [23]). X-ray fluorescence (XRF) spectra were collected using a Shimadzu EDX 720 XRF spectrometer. Diffuse reflectance spectra in the ultraviolet-visible region were recorded at room temperature between 200 and $800 \mathrm{~nm}$ using a Varian model Cary 5G in the diffuse reflectance mode (R). The band
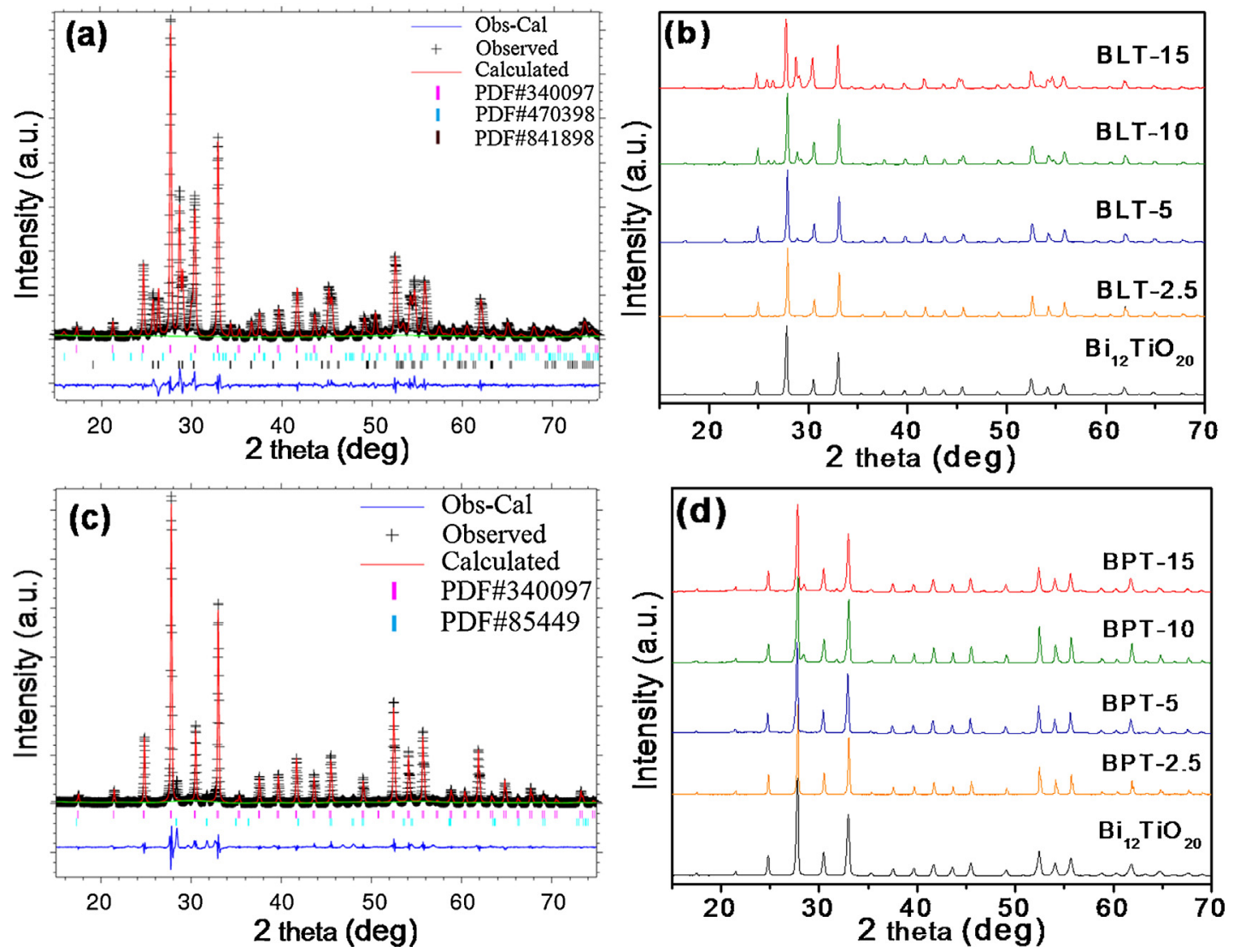

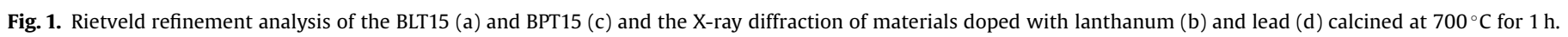


gaps of the samples were determined according to the method proposed by Tauc [24]. The morphology of the powders was characterized by scanning electron microscopy (SEM-FEG, ZEISS model-SUPRA 35) equipped with energy dispersive X-ray (EDX). Photoluminescence (PL) properties were measured with a Thermal Jarrel-Ash Monospec 27 monochromator and a Hamamatsu R446 photomultiplier. The excitation source was $350.7 \mathrm{~nm}$ wavelength of a krypton ion laser (Coherent Innova), keeping its power at $15 \mathrm{~mW}$. All measurements were performed at room temperature.

\subsection{Catalytic tests}

Eighty milliliters of a $10 \mathrm{mg} \mathrm{L}^{-1}$ solution of rhodamine $b(\mathrm{RhB})$ dye at pH 6.0 were mixed with $60 \mathrm{mg}$ of the catalyst and irradiated with ultraviolet and visible light inside a box. The light sources were set at a distance of $20 \mathrm{~cm}$ from the beaker containing the catalyst and $\mathrm{RhB}$ dye. The UV radiation used in this experiment was obtained with a medium-pressure mercury vapor lamp without a protection bulb (Osram HQL 400, $400 \mathrm{~W}$ with maximum intensity at $254 \mathrm{~nm}$ ) and the visible radiation was obtained with six lamps
(PHILIPS TL-D, $15 \mathrm{~W}$ with maximum intensity at $440 \mathrm{~nm}$ ). At the surface of solution the UV light intensity was $\approx 200 \mathrm{~mW} \mathrm{~cm}^{-2}$. For the adsorption test, we used the same conditions except for the presence of radiation. Reactions were monitored by UV-vis spectroscopy (JASCO V-660) at $554 \mathrm{~nm}$, using a commercial quartz cuvette.

\section{Results}

\subsection{Characterization}

To evaluate the behavior of the lanthanum and lead in the structure of $\mathrm{Bi}_{12} \mathrm{TiO}_{20}$, XRD measurements of materials calcined at $700^{\circ} \mathrm{C}$ for $1 \mathrm{~h}$ were carried out and the results were refined using the Rietveld method. The XRD patterns indicate the formation of a body-centered cubic structure with space group I23 belonging to the family of selenites, according to the crystallographic data base ICSD $\mathrm{N}^{\circ}$ 40313. It was observed that the selenite phase was predominant in all compositions, however, the BLT2.5, BLT5, BLT10 and BLT15 materials showed the formation of secondary phases related to the perovskite structure of bismuth titanate
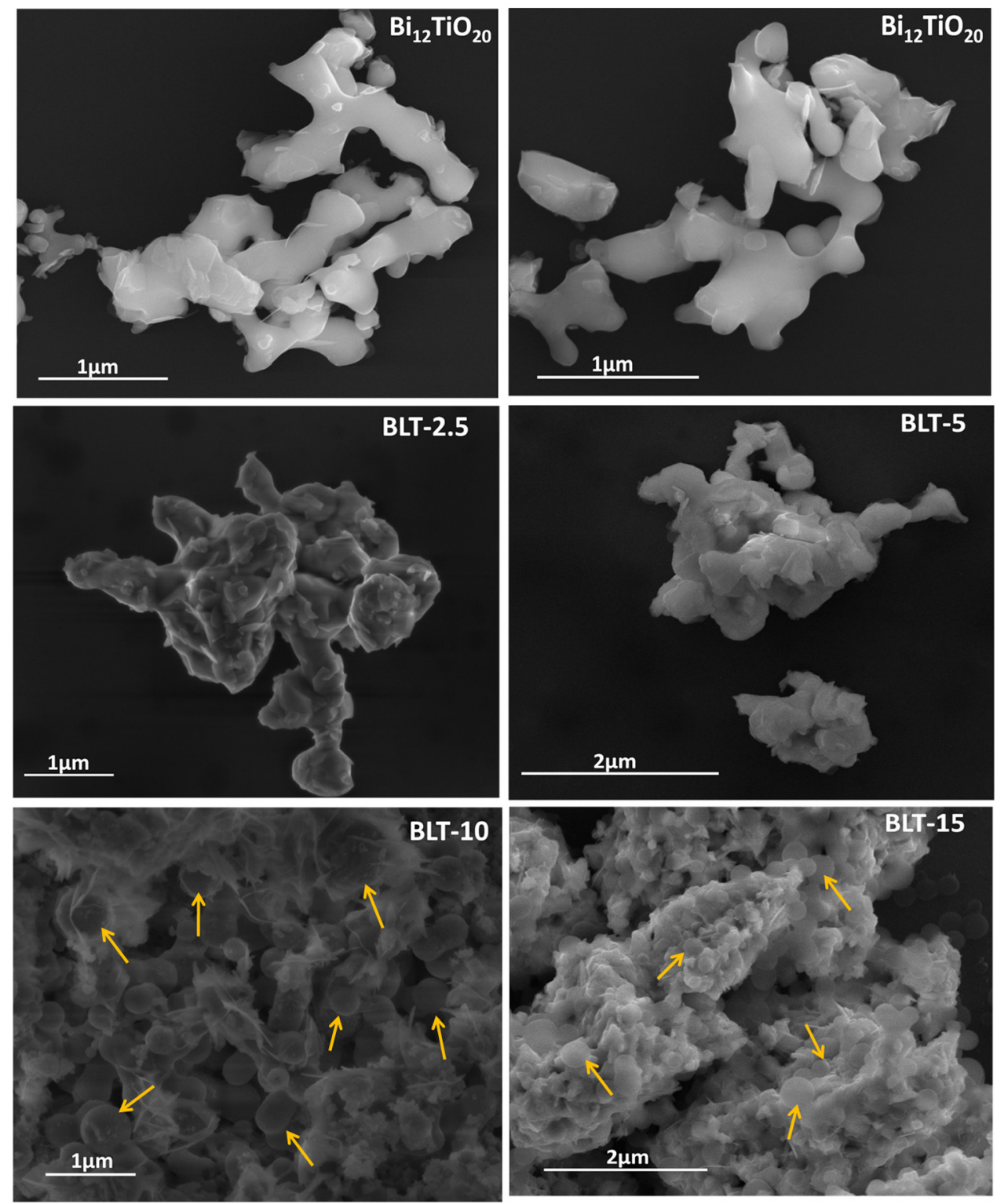

Fig. 2. Scanning electron microscopy of pure and La-doped materials calcined at $700^{\circ} \mathrm{C}$ for $1 \mathrm{~h}$. 
$\left(\mathrm{Bi}_{4} \mathrm{Ti}_{3} \mathrm{O}_{12}\right)\left(\right.$ ICSD N $\left.{ }^{\circ} 87811\right)$ and $\mathrm{Bi}_{0.7} \mathrm{La}_{0.3} \mathrm{O}_{1.5}$ (ICSD N $\left.{ }^{\circ} 202923\right)$. The BPT10 and BPT15 materials also showed the formation of a secondary phase related to the $\mathrm{Pb}_{0.5} \mathrm{Ti}_{0.5} \mathrm{O}_{1.33}$ (Supplementary Data) Fig. 1.

Figs. 2 and 3 show the scanning electron microscopy micrographs of the powders doped with lanthanum and lead, respectively. The BLT2.5 and BLT5 materials showed clusters of particles without a partially sintered defined morphology. However, the BLT10 and BLT15 materials show highly agglomerated nanoparticles with irregular shape together with well-defined spherical particles.

Fig. 3 shows the micrographs of materials doped with different lead concentrations. The particles showed no defined forms, only a morphological change occurring with the increase in the lead ion concentration, in which samples BPT15 and BPT10 showed partially sintered particles.

The compositions of the synthesized materials were measured by X-ray fluorescence analysis. The amounts of lead in the doped samples are in good agreement with the expected composition (Table 1). However, the results obtained from La-doped materials presented a molar ratio of lanthanum above the calculated quantity, this difference is due to a decreased formation of titanium oxide. In the same table the values of specific surface area
(BET) are presented. It was observed that the materials had low surface area and there is no significant variation with different dopant concentrations.

The optical absorption of the pure and, La- and Pb-doped bismuth titanate were measured by UV-vis spectroscopy in diffuse reflectance to verify the influence of these elements in the electronic structure of bismuth titanate. The absorption edge $(\lambda)$ of pure $\mathrm{Bi}_{12} \mathrm{TiO}_{20}$ was estimated to be at $490 \mathrm{~nm}$, while the La- and Pbdoped bismuth titanate powders showed values shifted to higher wavelengths (Fig. 4(a) and (b)), strongly suggesting the influence of the doping element on the optical characteristics of the material.

The onset absorption values are determined by the linear extrapolation of the steep part of the UV absorption toward the base line. The optical band gap $\left(E_{\mathrm{g}}\right)$ of the samples can be calculated on the basis of the optical absorption spectra by the following equation (Eq. (1)):

$(\alpha h v)^{n}=\mathrm{A}\left(h v-E_{\mathrm{g}}\right)$

where $h v$ is the photon energy, A is the related to the effective masses associated with the valence and conduction bands, $n$ is either $n=2$ for an indirect allowed transition or $n=1 / 2$ for the direct forbidden transition and $\alpha$ is the absorption coeffient obtained using the Kubelka-Munk transformation of measures
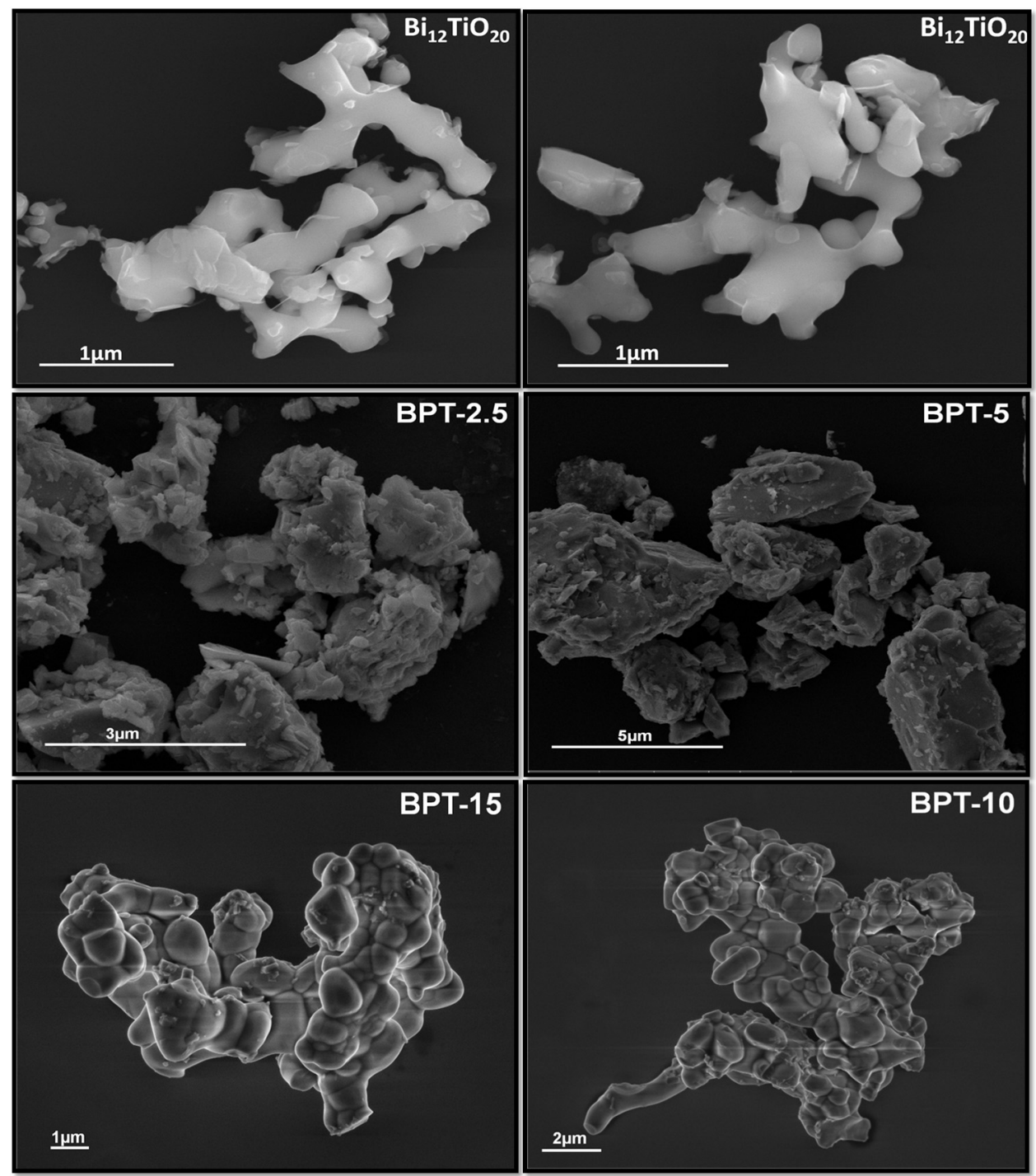

Fig. 3. Scanning electron microscopy of pure and Pb-doped materials calcined at $700^{\circ} \mathrm{C}$ for $1 \mathrm{~h}$. 
Table 1

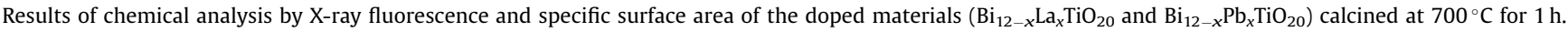

\begin{tabular}{|c|c|c|c|c|c|c|c|}
\hline Material & Calculated La (mol) & XRF La (mol) & Area $\left(\mathrm{m}^{2} / \mathrm{g}\right)$ & Material & Calculated $\mathrm{Pb}(\mathrm{mol})$ & $\mathrm{XRF} \mathrm{Pb}(\mathrm{mol})$ & Area $\left(\mathrm{m}^{2} / \mathrm{g}\right)$ \\
\hline $\mathrm{Bi}_{12} \mathrm{TiO}_{20}$ & - & - & 2.49 & $\mathrm{Bi}_{12} \mathrm{TiO}_{20}$ & - & - & 2.49 \\
\hline BLT-2.5 & 0.30 & 0.65 & 2.10 & BPT-2.5 & 0.30 & 0.43 & 1.14 \\
\hline BLT-5 & 0.60 & 0.92 & 3.31 & BPT-5 & 0.60 & 0.68 & 3.07 \\
\hline BLT-10 & 1.20 & 1.49 & 8.03 & BPT-10 & 1.20 & 1.31 & 2.15 \\
\hline BLT-15 & 1.50 & 2.15 & 1.89 & BPT-15 & 1.50 & 1.37 & 2.45 \\
\hline
\end{tabular}
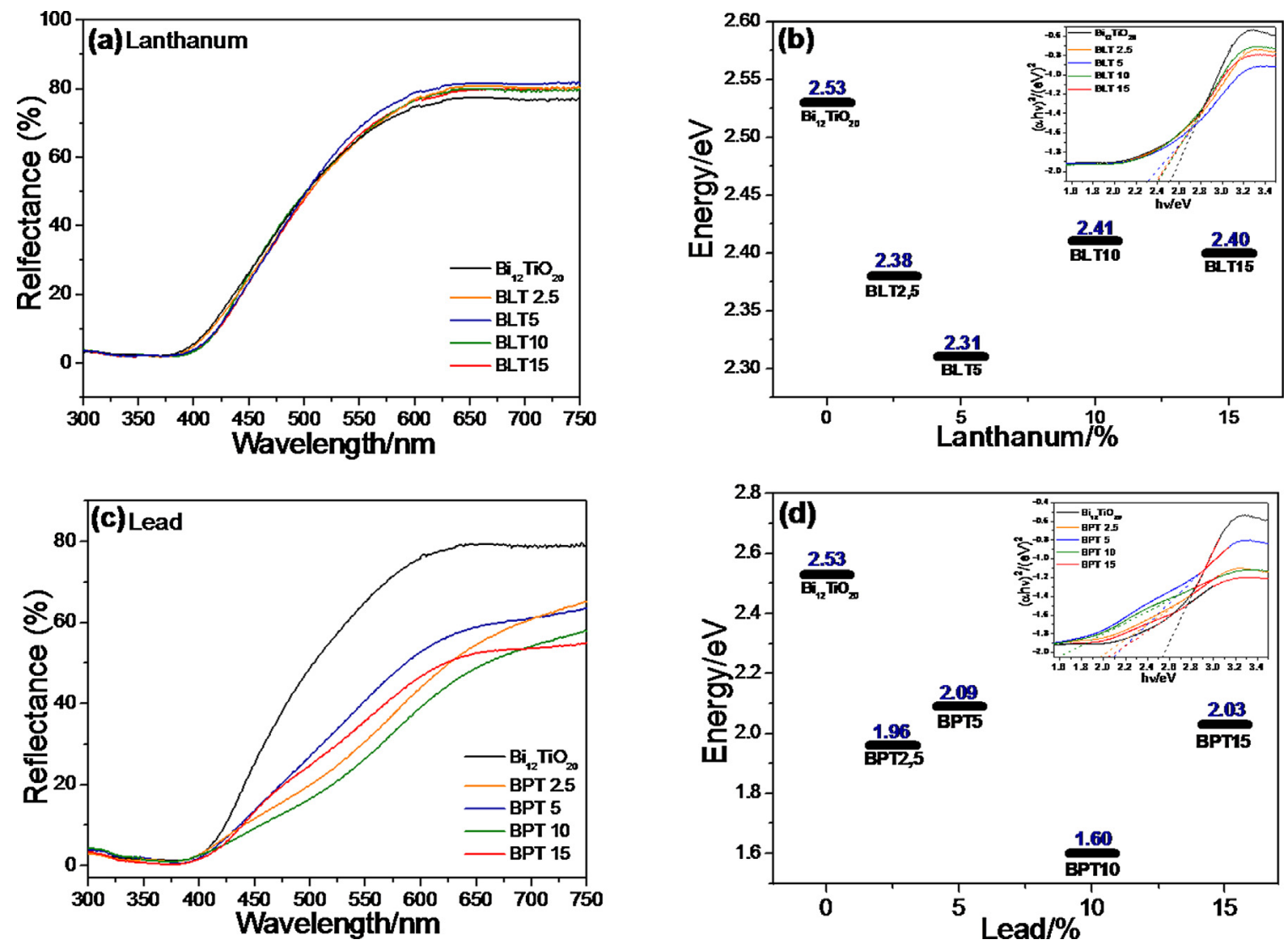

Fig. 4. UV-vis diffuse reflectance spectra of La- (a) and Pb-doped (c) bismuth titanate and their respective band gap energies (b) and (d).
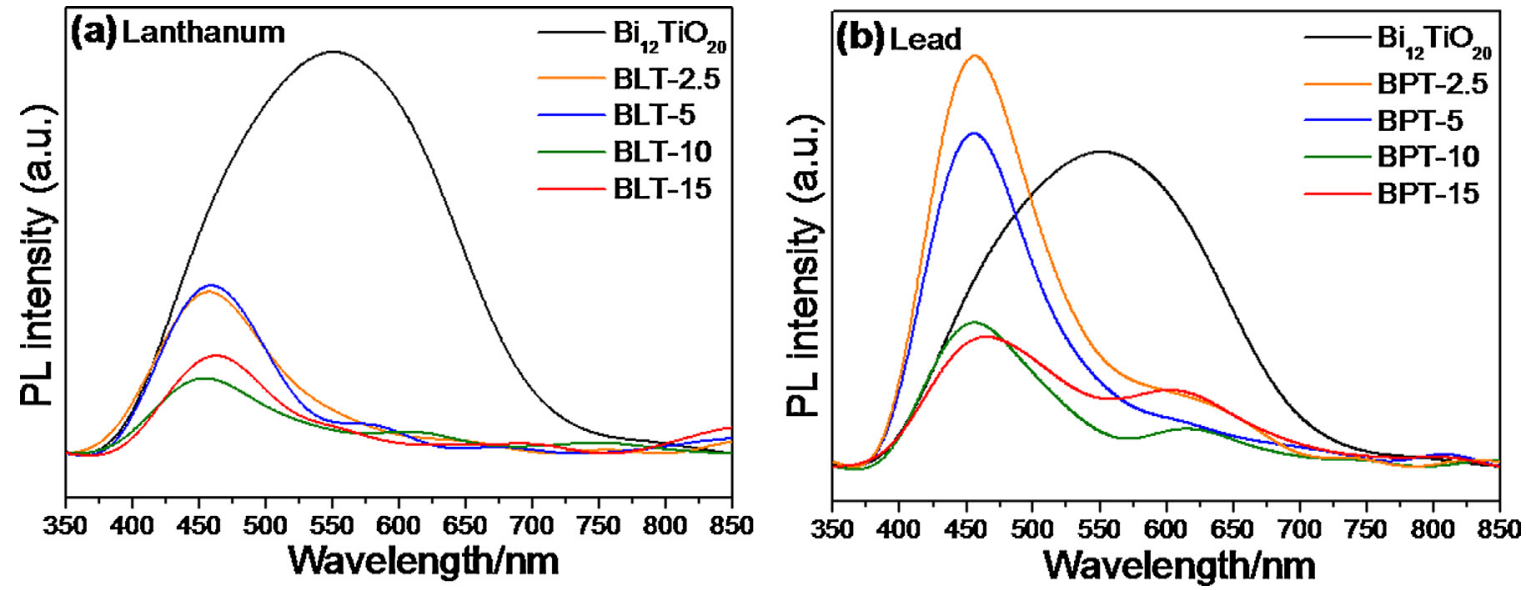

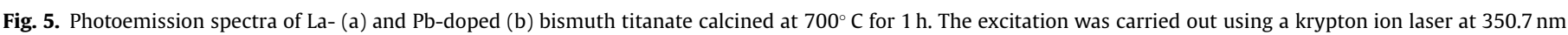
wavelength. 

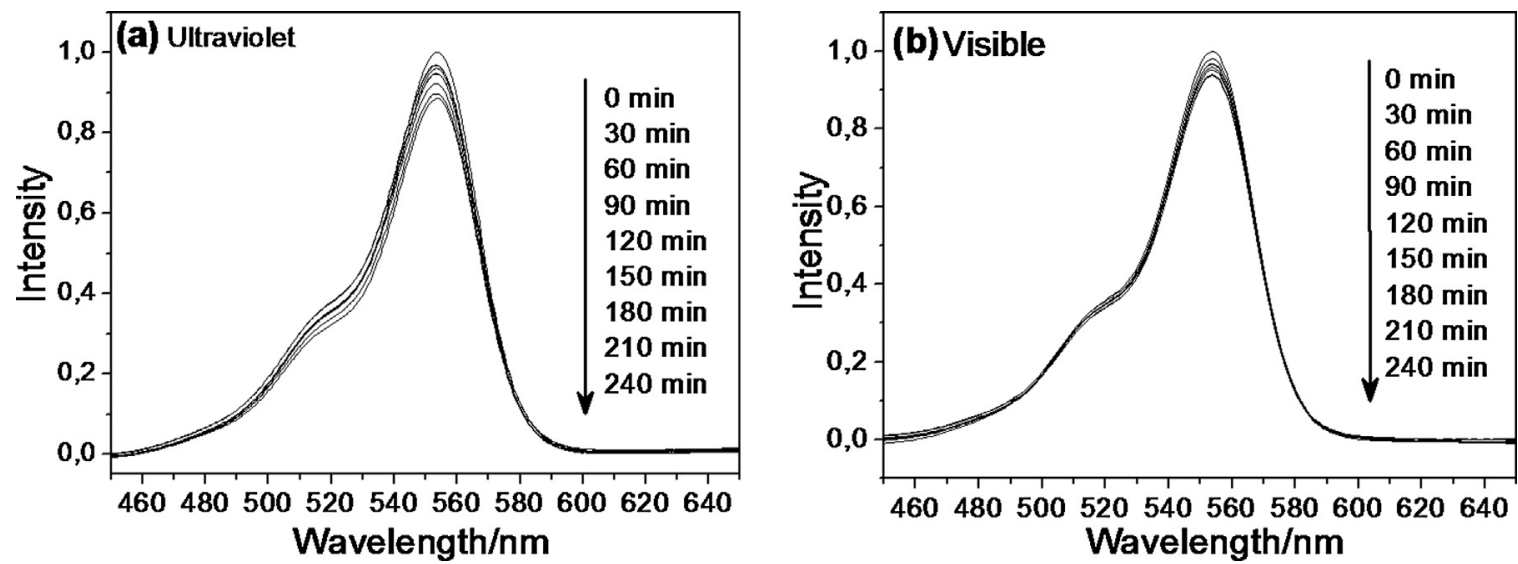

Fig. 6. Absorbance spectra changes of RhB solution $(10 \mathrm{mg} / \mathrm{L})$ after different irradiation times without catalyst under UV (a) and visible (b) radiation.

reflectance (Eq. (2)), where $\mathrm{R}$ is reflectancy (\%). Plotting $(\alpha h v)^{2}$ versus $h v$ based on the spectral response gives the extrapolated corresponding $E_{\mathrm{g}}$ values.

$\alpha=\frac{(1-R)^{2}}{2 R}$

Fig. 4(b) and (d) shows the band gap energy values for La- and $\mathrm{Pb}$-doped bismuth titanate respectively. It was observed that, compared to the pure bismuth titanate, the values found for all doped material were lower. This effect can be explained by the overlap of the wave functions of the electrons bound to the dopant. This energy overlay requires the formation of an energy band rather than a discrete level, decreasing the band gap energy of the materials Fig. 5.

The $\mathrm{Bi}_{12} \mathrm{TiO}_{20}$ spectrum showed a broad band in the visible region $375-750 \mathrm{~nm}$ with a maximum emission at $551 \mathrm{~nm}$ (green emission). It was observed that after the doping there occurs a shift of maximum emission to lower wavelengths of approximately $450 \mathrm{~nm}$ (blue emission). However, the BPT15 and BPT10 materials showed a second emission band at approximately $625 \mathrm{~nm}$ (orange/ red emission). These emissions are related to the existence of intermediate energy levels in the band gap of semiconductors called shallow and deep holes. The deep holes are considered emission centers responsible for the green, yellow, orange and red
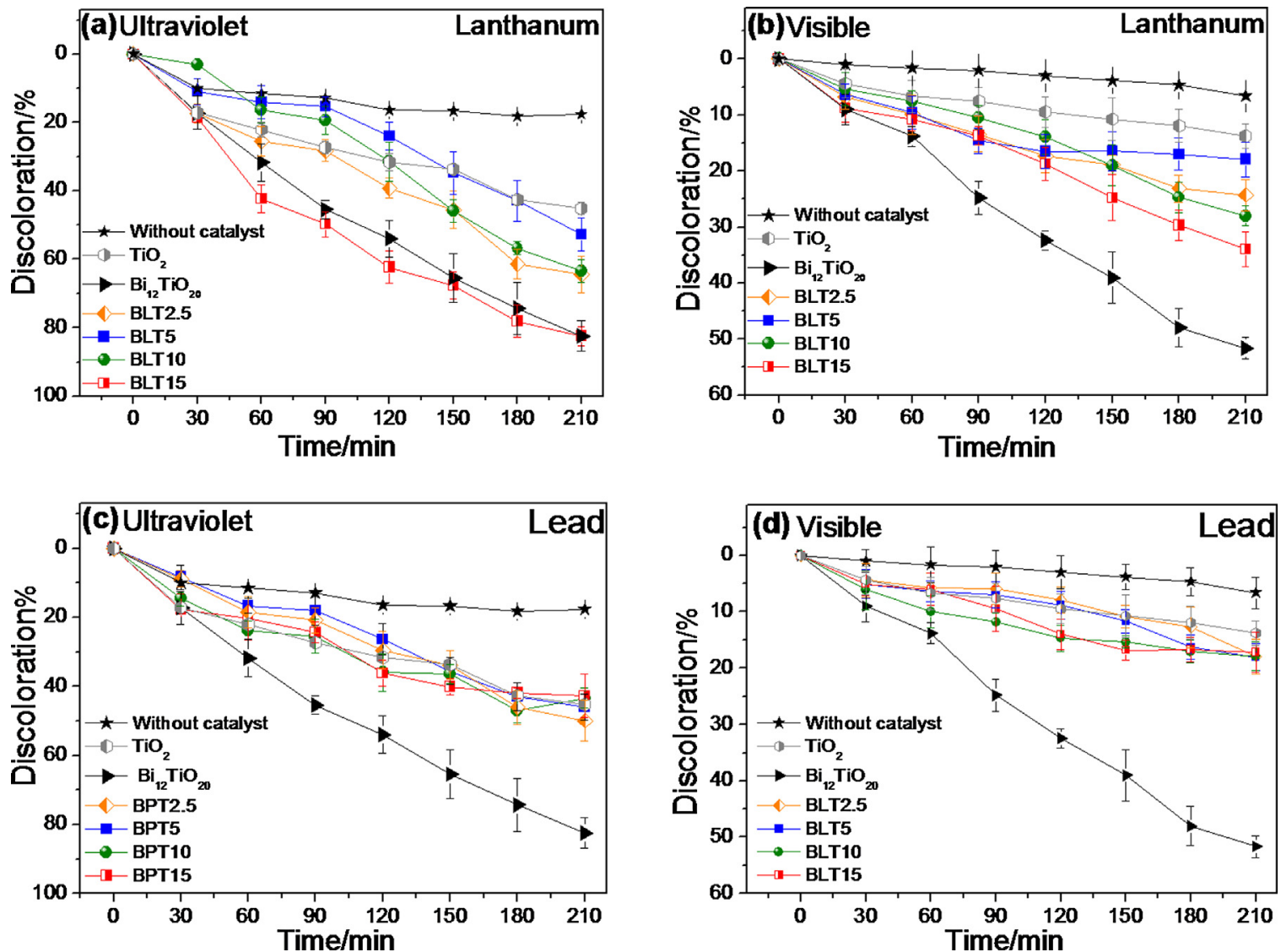

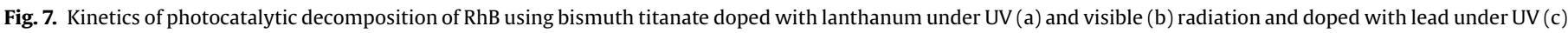
and visible $(\mathrm{d})$ radiation. 

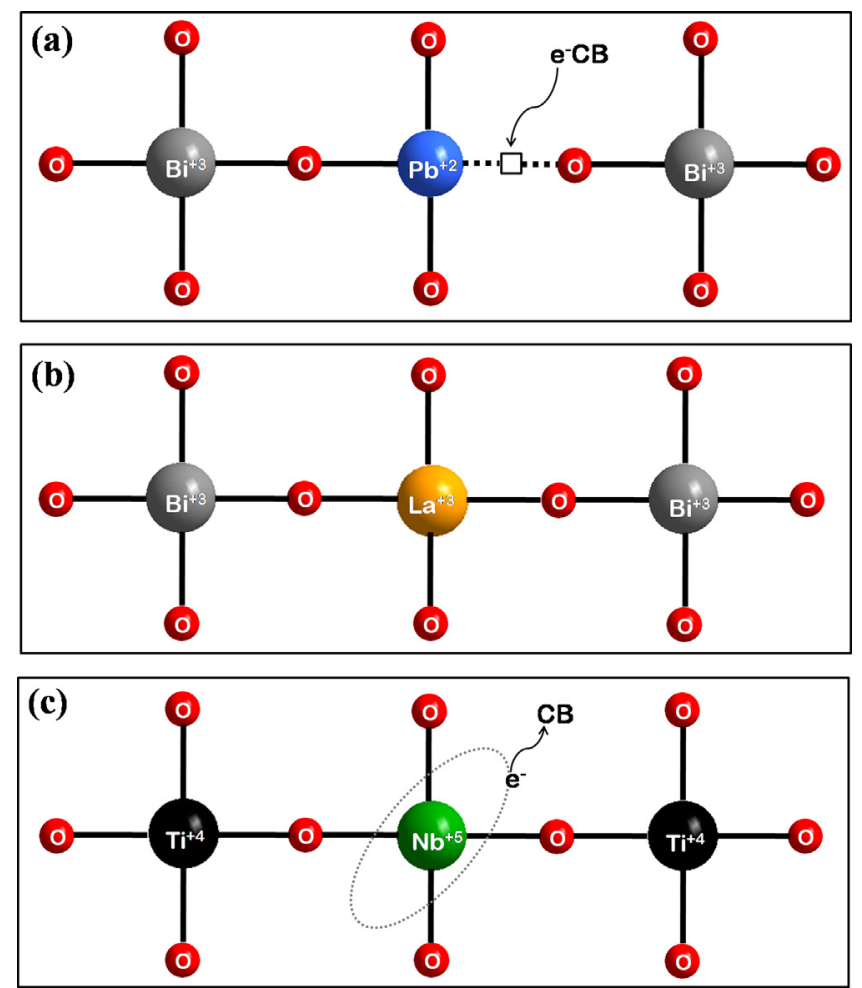

Fig. 8. Doping scheme of bismuth titanate with di- (a), tri- (b) and tetra-valent (c) cations.

PL at room temperature, while the shallow holes are associated to the violet and blue emissions [25].

\subsection{Catalytic tests}

The first test performed was the direct photolysis of RhB. This process is related to the degradation of organic compounds accomplished solely by the presence of electromagnetic radiation. It was observed that after 240 min of reaction, there was a $15 \%$ of the dye solution discoloration under UV (Fig. 6(a)) and 6\% under visible radiation (Fig. 6(b)). It is important to emphasize that the photocatalysis results presented below include the effects of photolysis.

The second test performed was the adsorption of $\mathrm{RhB}$ dye in the absence of electromagnetic radiation to determine the minimum contact time between $\mathrm{RhB}$ and the material needed to achieve the chemical equilibrium of the adsorption and desorption process. This test is important to ensure the point at which discoloration of the RhB solution is caused solely by the photocatalytic process without the influence of the adsorption process. The results showed that approximately $7 \%$ solution discoloration occurred at $210 \mathrm{~min}$, and equilibrium was reached at $90 \mathrm{~min}$ of reaction. Thus, in all photocatalytic experiments, the dye solution was kept in the dark for $90 \mathrm{~min}$ under stirring. After this time, the equilibrium concentration of the dye solution was determined and considered as time zero.

The photocatalytic activity of La- and Pb-doped bismuth titanate obtained by the OPM method was evaluated in the discoloration capacity of the RhB solution under UV and visible radiation (Fig. 7).

The La-doped materials showed higher photocatalytic activity when compared with the Pb-doped materials, showing 83\% solution discoloration at $210 \mathrm{~min}$ of reaction with BLT15 under UV radiation. However, the Pd-doped materials did not show good photocatalytic activity under UV radiation, showing only 50,46 ,
43 and $42 \%$ discoloration of the solution at $210 \mathrm{~min}$ for the BPT2.5, BPT5, BPT10, and BPT15 respectively.

In both studied cases, the efficiency of photodegradation dramatically decreased in the presence of the dopants. The decrease was faster in the case of Pb-doped materials (Fig. 7 (d)). The reduction in the photocatalytic activity may be related to band gap energy decrease of the materials by the modifed redox potential of $\mathrm{BC}$ and $\mathrm{BV}$ of the semiconductors, in which the hole $\left(h^{+}\right)$potential in BV generated in the electron transfer to BC is not enough to generate $\mathrm{HO}^{\bullet}$ radicals through the oxidation of water. The ideal band gap for any visible-light driven photocatalyst is around $2.0 \mathrm{eV}$ for the effective utilization of the solar spectrum. However, the $\mathrm{CB}$ has to be higher (more negative) than the oxygen reduction potential $\left(\mathrm{O}_{2} / \mathrm{O}_{2}{ }^{--} E^{\circ}=-0,33 \mathrm{~V}\right)$, while the $\mathrm{VB}$ has to be lower (more positive) than the water oxidation potential $\left(\mathrm{H}_{2} \mathrm{O} / \mathrm{HO}^{\bullet}\right.$ $\left.E^{\circ}=-2,73 \mathrm{~V}\right)[26]$.

Another factor that may have contributed to the decrease in photocatalytic activity is related to the presence of lead in the bismuth titanate structure, in which the dopant may be more likely to serve as recombination centers than as trap sites for possible transfer charge from bulk to the surface [27]. In the case of substitutional doping of $\mathrm{Bi}_{12-x} \mathrm{~Pb}_{x} \mathrm{TiO}_{20}$ by $\mathrm{Pb}^{2+}$, according to Fig. 8 , this doping agent creates one acceptor center $\mathrm{A}$ :

$\mathrm{Bi}_{12-\chi} \mathrm{Pb}_{x} \mathrm{TiO}_{20}+h v \rightarrow e^{-}+h^{+}$
$\left(-\mathrm{Pb}^{2+}-\right)+e^{-} \leftrightarrows\left[\left(-\mathrm{Pb}^{2+}-\right) e^{-}\right]$

Equilibrium (4) can be written as:

$\mathrm{A}+e^{-} \leftrightarrows \mathrm{A}^{-}$

The filled acceptor centers become negatively charged and consequently attract photo-holes and become empty after neutralization:

$\mathrm{A}^{-}+h^{+} \leftrightarrows A$

The resulting mass balance gives:

$\mathrm{e}^{-}+h^{+} \leftrightarrows N+$ heat $(N=$ neutral center $)$

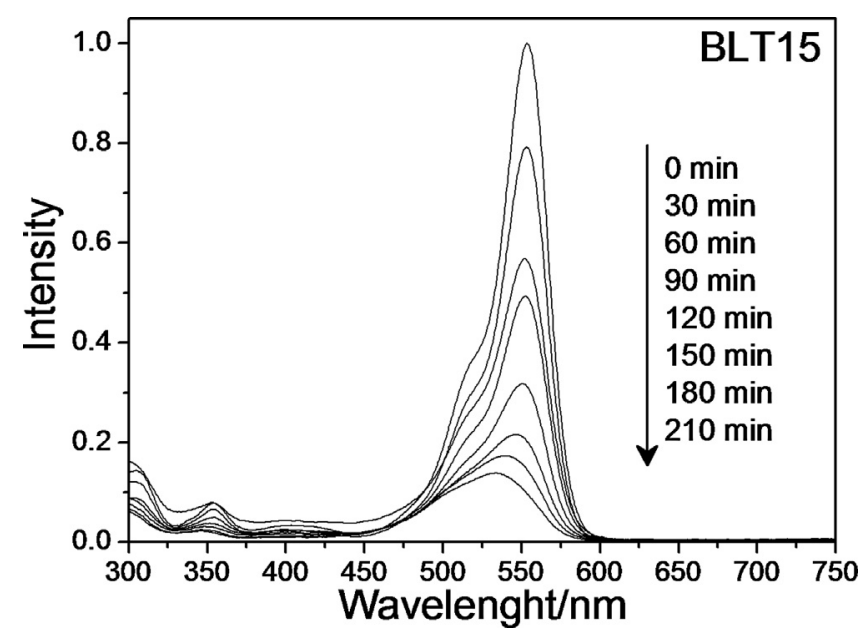

Fig. 9. Absorbance spectra of the RhB solution after different irradiation times in the presence of BLT15 catalyst under UV radiation. 
Table 2

Photocatalytic reaction constants of the materials.

\begin{tabular}{|c|c|c|c|c|c|c|}
\hline \multirow[t]{2}{*}{ Material } & \multicolumn{3}{|l|}{ Ultraviolet } & \multicolumn{3}{|l|}{ Visible } \\
\hline & $\mathrm{k} \times 10^{-3}\left(\min ^{-1}\right)$ & Error $\left(10^{-4}\right)$ & $\mathrm{R}^{2}$ & $\mathrm{k} \times 10^{-3}\left(\mathrm{~min}^{-1}\right)$ & Error $\left(10^{-4}\right)$ & $\mathrm{R}^{2}$ \\
\hline $\mathrm{Bi}_{12} \mathrm{TiO}_{20}$ & 8.05 & \pm 4 & 0.9913 & 3.58 & \pm 1 & 0.9898 \\
\hline BLT 2.5 & 4.82 & \pm 3 & 0.9915 & 1.30 & \pm 1 & 0.9793 \\
\hline BLT 5 & 2.96 & \pm 5 & 0.8109 & 0.89 & \pm 2 & 0.8257 \\
\hline BLT 10 & 4.97 & \pm 5 & 0.9441 & 1.54 & \pm 1 & 0.9736 \\
\hline BLT 15 & 8.24 & \pm 3 & 0.9915 & 1.90 & \pm 1 & 0.9784 \\
\hline BPT 2.5 & 3.26 & \pm 2 & 0.9719 & 0.80 & \pm 1 & 0.9233 \\
\hline BPT 5 & 3.00 & \pm 2 & 0.9771 & 0.88 & \pm 1 & 0.9440 \\
\hline BPT 10 & 2.81 & \pm 3 & 0.9262 & 0.88 & \pm 1 & 0.9087 \\
\hline BPT 15 & 2.65 & \pm 3 & 0.9251 & 0.95 & \pm 1 & 0.9271 \\
\hline
\end{tabular}

The photocatalytic activity of different samples can be quantitatively evaluated by comparing the apparent reaction rate constants. In a heterogeneous solid-liquid reaction, the photocatalytic degradation of RhB is a pseudo-first-order reaction, and its kinetic equation may be expressed as follows [28].

$\ln \frac{C_{0}}{C_{\mathrm{t}}}=k_{\mathrm{app}} t$

where $C_{0}$ corresponds to the initial concentration of RhB before UV and visible radiation, $k_{\mathrm{app}}$ is the apparent rate constant and $C_{\mathrm{t}}$ is the concentration of RhB after a time $(t)$ of UV and visible irradiation treatment.

Fig. 9 presents the temporal evolution of the spectral changes during the photodegradation of RhB over BNT15 under UV radiation. The absorption peak of RhB at $664 \mathrm{~nm}$ underwent a rapid decrease without a hypsochromic shift and without a new absorption band emerging even in the ultraviolet range, which indicates that RhB molecules were mineralized without any organic intermediates under our employed conditions Table 2.

\section{Conclusion}

Pure and doped bismuth titanate with silenite phase can be easily synthesized by the OPM method. Two cationic dopants have been studied: $\mathrm{La}^{3+}$ and $\mathrm{Pb}^{2+}$, while the doping level ranged in a large domain. In all cases, there is preferential formation of the selenite phase of bismuth titanate as identified by the Rietveld refinement of the XRD.

Increasing the dopant concentration in the bismuth titanate structure caused a change in the morphology and a decreased band gap energy of the materials. The photoemission spectra suggests that the presence of dopants create different energy states located within the bismuth titanate band gap.

Doping in with lead had a detrimental effect on the photocatalytic efficiency of the bismuth titanate. The reduction in the photocatalytic activity can be related to the position of valence band of the photocatalyst and the mobility of photogenerated carriers, hindering the generation of the hydroxyl radical that is the main responsible agent for the degradation of organic compounds.

\section{Acknowledgement}

This study was supported by the INCTMF/CMDMF-CEPID (grant \#2013/07296-2). We also acknowledge the Brazilian agencies CAPES, CNPq and São Paulo Research Foundation-FAPESP (grants \#2010/20129-0 and \#2012/07067-0).

\section{Appendix A. Supplementary data}

Supplementary data associated with this article can be found, in the online version, at http://dx.doi.org/10.1016/j. jphotochem.2015.07.012.

\section{References}

[1] A. Kunz, P. Peralta-Zamoura, Novas tendências no tratamento de efuentes têxteis, Quím. Nova 25 (2002) 78.

[2] A.M. Amat, A. Arques, M.A. Miranda, F. Lopez, Use of ozone and/or UV in the treatment of effluents from board paper industry, Chemosphere 60 (2005) 1111.

[3] P.Y. Chan, M. Gamal El-Din, J.R. Bolton, A solar-driven UV/Chlorine advanced oxidation process, Water Res. 46 (2012) 5672.

[4] A. Katsoni, H.T. Gomes, L.M. Pastrana-Martínez, J.L. Faria, J.L. Figueiredo, D Mantzavinos, A.M.T. Silva, Degradation of trinitrophenol by sequential catalytic wet air oxidation and solar $\mathrm{TiO}_{2}$ photocatalysis, Chem. Eng. J. 172 (2011) 634.

[5] A.C. Affam, M. Chaudhuri, Degradation of pesticides chlorpyrifos, cypermethrin and chlorothalonil in aqueous solution by $\mathrm{TiO}_{2}$ photocatalysis, J. Environ. Manage. 130 (2013) 160.

[6] O. Prieto, J. Fermoso, Y. Nuñez, J.L. del Valle, R. Irusta, Decolouration of textile dyes in wastewaters by photocatalysis with $\mathrm{TiO}_{2}$, Sol. Energy 79 (2005) 376

[7] K. Nakata, A. Fujishima, $\mathrm{TiO}_{2}$ photocatalysis: design and applications, J. Photochem. Photobiol. C 13 (2012) 169.

[8] M. Pelaez, N.T. Nolan, S.C. Pillai, M.K. Seery, P. Falaras, A.G. Kontos, P.S.M. Dunlop, J.W.J. Hamilton, J.A. Byrne, K. O’Shea, M.H. Entezari, D.D. Dionysiou, A review on the visible light active titanium dioxide photocatalysts for environmental applications, Appl. Catal. B 125 (2012) 331.

[9] X. Zhu, J. Zhang, F. Chen, Study on visible light photocatalytic activity and mechanism of spherical $\mathrm{Bi}_{12} \mathrm{TiO}_{20}$ nanoparticles prepared by low-power hydrothermal method, Appl. Catal. B 102 (2011) 316.

[10] X. Zhu, J. Zhang, F. Chen, Hydrothermal synthesis of nanostructures $\mathrm{Bi}_{12} \mathrm{TiO}_{20}$ and their photocatalytic activity on acid orange 7 under visible light, Chemosphere 78 (2010) 1350.

[11] T. Asai, E.R. Camargo, M. Kakihana, M. Osada, A novel aqueous solution route to the low-temperature synthesis of $\mathrm{SrBi}_{2} \mathrm{Nb}_{2} \mathrm{O}_{9}$ by use of water-soluble $\mathrm{Bi}$ and Nb complexes, J. Alloys Compd. 309 (2000) 113.

[12] T. Kidchob, L. Malfatti, D. Marongiu, S. Enzo, P. Innocenzi, Sol-gel processing of $\mathrm{Bi}_{2} \mathrm{Ti}_{2} \mathrm{O}_{7}$ and $\mathrm{Bi}_{2} \mathrm{Ti}_{4} \mathrm{O}_{11}$ films with photocatalytic activity, J. Am. Ceram. Soc. 93 (2010) 2897.

[13] J.-H. Park, J.-S. Bae, B.-C. Choi, J.-H. Jeong, Effect of Nb doping of ferroelectric properties of $\mathrm{Bi}_{3.25} \mathrm{La}_{0.75} \mathrm{Ti}_{3} \mathrm{O}_{12}$ ceramics, J. Appl. Phys. 97 (2005) 064110.

[14] A.L. Hector, S.B. Wiggin, Synthesis and structural study of stoichiometric $\mathrm{Bi}_{2} \mathrm{Ti}_{2} \mathrm{O}_{7}$ pyrochlore, J. Solid State Chem. 177 (2004) 139.

[15] S.J. Henderson, O. Shebanova, A.L. Hector, P.F. McMillan, M.T. Weller, Structural variations in pyrochlore-structured $\mathrm{Bi}_{2} \mathrm{Hf}_{2} \mathrm{O}_{7} \quad \mathrm{Bi}_{2} \mathrm{Ti}_{2} \mathrm{O}_{7}$ and $\mathrm{Bi}_{2} \mathrm{Hf}_{2-\chi} \mathrm{Ti}_{x} \mathrm{O}_{7}$ solid solutions as a function of composition and temperature by neutron and X-ray diffraction and Raman spectroscopy, Chem. Mater. 19 (2007) 1712.

[16] J. Hou, Y. Qu, D. Krsmanovic, R.V. Kumar, Peroxide-based route assisted with inverse microemulsion process to well-dispersed $\mathrm{Bi}_{4} \mathrm{Ti}_{3} \mathrm{O}_{12}$ nanocrystals, $\mathrm{J}$. Nanopart. Res. 12 (2009) 1797.

[17] E.R. Camargo, M.G. Dancini, M. Kakihana, The oxidant peroxo method (OPM) as a new alternative for the synthesis of lead-based and bismuth-based oxides, J. Mater. Res. 29 (2014) 131

[18] A.E. Nogueira, E. Longo, Leite, Synthesis and photocatalytic properties of bismuth titanate with different structures via oxidant peroxo method (OPM), J. Colloid Interface Sci. 415 (2014) 89.

[19] E.R. Camargo, M. Kakihana, Peroxide-based route free from halides for the synthesis of lead titanate powder, Chem. Mater. 13 (2001) 1181.

[20] A.C. Larson, R.B. Von Dreele, General Structure Analysis System (GSAS), Los Alamos National Laboratory, Los Alamos, NM, 2004.

[21] C.H. Hervoches, P. Lightfoot, A variable-temperature powder neutron diffraction study of ferroelectric $\mathrm{Bi}_{4} \mathrm{Ti}_{3} \mathrm{O}_{12}$, Chem. Mater. 11 (1999) 3359.

[22] V.A. Sarin, E.E. Rider, V.N. Kanepit, N.N. Bydanov, V.V. Volkov, Y.F. Kargin, V.M. Skorikov, Neutron structural investigation of single crystal of bismuth titanate $\mathrm{Bi}_{12} \mathrm{TiO}_{20}$, Kristallografiya 34 (1989) 628.

[23] D. Mercurio, M.E. Farissi, J.C. Champarnaud-Mesjard, B. Frit, P. Conflant, G. Roult, Etude structurale par diffraction X sur monocristal et diffraction neutronique sur poudre de l'oxyde mixte $\mathrm{Bi}_{0.7} \mathrm{La}_{0.3} \mathrm{O}_{1.5}$, J. Solid State Chem. 80 (1989) 133. 
[24] G.P. Joshi, N.S. Saxena, R. Mangal, A. Mishra, T.P. Sharma, Band gap determination of Ni-Zn ferrites, Bull. Mater. Sci. 26 (2003) 387.

[25] J.L. Lyons, A. Janotti, C.G. Van de Walle, Shallow versus deep nature of Mg acceptors in nitride semiconductors, Phys. Rev. Lett. 108 (2012) 156403.

[26] P. Wardman, Reduction potentials of one-electron couples involving free radicals in aqueous solution, J. Phys. Chem. Ref. Data 18 (1989) 1637.
[27] J.-M. Herrmann, Detrimental cationic doping of titania in photocatalysis: why chromium $\mathrm{Cr}^{3+}$-doping is a catastrophe for photocatalysis, both under UV- and visible irradiations, New J. Chem. 36 (2012) 883.

[28] V.R. de Mendonça, C. Ribeiro, Influence of $\mathrm{TiO}_{2}$ morphological parameters in dye photodegradation: a comparative study in peroxo-based synthesis, Appl. Catal. B 105 (2011) 298. 